\section{GDC OPENS ETHICAL ADVERTISING CONSULTATION}

The General Dental Council (GDC) wants to hear dental professionals' views on the draft version of a guidance document about advertising. The GDC wants to ensure that all information or publicity materials such as flyers or adverts about dental services are legal, decent, honest and truthful.

The GDC's ethical guidance Standards for dental professionals sets expectations for registrants, which include working within your knowledge, professional competence and physical abilities; not making any claims which could mislead patients; and justifying the trust that your patients, the public and your colleagues have in you by always acting honestly and fairly.

'We often get queries from members

\section{NEW CALL FOR DCPs BY GDC}

The General Dental Council (GDC) has issued a fresh push to recruit dental care professionals (DCPs) to sit on its new Fitness to Practise panel. DCPs have until 3 September to apply to become a member of the panel.

The Fitness to Practise panel is central to the GDC's work in protecting patients. Successful candidates will be expected to sit on panels in public hearings, hear applications for restoration to the GDC registers, and hear appeals against registration decisions. sionals' websites. of the public concerned or worried about the information they've seen,' said GDC Chair Alison Lockyer. 'We plan to ask patients what they think, but we also need to know the views of those we regulate. We hope that dental professionals and other people linked to dentistry will take the time to tell us what they think.'

The consultation, which opened to everyone on 8 July 2010 and will run to 1 October 2010, looks at a number of issues regarding advertising, such as using specialist titles; advertising the provision of dental appliances; and information which should be on profes-

The consultation can be found at www.gdc-uk.org.

Fitness to Practise panel members are paid £353 a day and are reimbursed for their expenses. It is a part time role, with members sitting for around 20 days a year and members allocated to a particular hearing well in advance.

Alison Lockyer, GDC Chair, called for dental nurses, technicians, hygienists and therapists to come forward and said: 'Decision making, working in a team, respecting confidential information, being trustworthy and communicating clearly - these are just some of the qualities a panel member should have. If you're interested you can find out more at www.gdcpanellists.com.'

\section{BRITS SCOOP PRIZES IN BARCELONA}

Two well known contributors to the British Dental Journal (BDJ) were recognised for their work at the International Association for Dental Research's (IADR's) 88th General Session \& Exhibition in Barcelona on 14 July 2010.

Professor Martin Downer received the IADR Behavioral, Epidemiological and Health Services Research Award. Dr Paula Moynihan was presented with the IADR Geriatric Oral Research Award.

Professor Downer is an honorary professor at the Eastman Dental Institute, University College London and the University of Manchester. With more than 35 years' experience in the field of health services research, his main areas of interest have centred around the epidemiology of two contrasting oral diseases of oral health importance: dental caries and oral cancer.

Dr Moynihan is a Reader in nutrition and oral health at Newcastle University. Her seminal work identifying edentulism as a key risk variable for low intakes of dietary fibre and of fruits and vegetables paved the way for a series of studies using novel techniques to identify an individual's awareness of their diet and their willingness to change.

Dr Paul Cooper, a senior lecturer in molecular biology at the University of Birmingham, received the IADR Young Investigator Award, designed to stimulate basic research.

\title{
OPEN-MINDED DENTISTS EXPLORE COMPLEMENTARY TECHNIQUES
}

The 11th Annual Rural Dental Conference aimed to explore 'complementary' techniques in the world of dentistry, such as acupuncture, hypnosis, homeopathy, herbalism and propolis together with the role of 'golden proportions' in cosmetic work.

Organised by the Welsh Rural Postgraduate Unit and held at Gregynog Hall, near Newtown in Mid-Wales, the theme of the conference was 'Open mouth, open mind'.

'The General Dental Council has advised that dental teams are familiar with complementary techniques to be better able to advise their patients,' said Dr Charles Vaughan Jones, postgraduate dental tutor for Rural Wales. 'However, the general feeling after the day was that the techniques that had been discussed were of more than academic interest.

Speakers included Phil Wander, who outlined the use of homeopathy in his practice and extolled the virtues of propolis, a natural secretion of the honey bee.

Tom Thayer, Consultant Oral Surgeon and also chair of the British Dental Acupuncture Society, described the valuable part that acupuncture plays in his everyday work.
Val Walters spoke on hypnosis in dentistry and presented a film of demanding dental work that relied solely on hypnosis for analgesia.

Next year's Rural Dental Conference will also be held at Gregynog Hall, on 10 June 2011. 